\title{
Beta-cells from patients with COVID-19 and from isolated human islets exhibit ACE2, DPP4, and TMPRSS2 expression, viral infiltration and necroptotic cell death
}

\section{Charlotte Steenblock}

Technische Universität Dresden

\section{Stefanie Richter}

Institute of Virology, Medical Faculty Carl Gustav Carus at the Technical University of Dresden

llona Berger

Medical Faculty Carl Gustav Carus at the Technical University of Dresden

\section{Marko Barovic}

Paul Langerhans Institute Dresden (PLID)

\section{Janine Schmid}

Department of Internal Medicine III, Medical Faculty Carl Gustav Carus at the Technical University of Dresden

\section{Undine Schubert}

Department of Internal Medicine III, Medical Faculty Carl Gustav Carus at the Technical University of Dresden

\section{Natalia Jarzebska}

Department of Internal Medicine III, Medical Faculty Carl Gustav Carus at the Technical University of Dresden

\section{Anne von Mässenhausen}

Department of Internal Medicine III, Medical Faculty Carl Gustav Carus at the Technical University of Dresden

\section{Andreas Linkermann}

University Hospital Carl Gustav Carus

\section{Annette Schürmann}

German Institute of Human Nutrition (DIfE) https://orcid.org/0000-0002-4113-4377

\section{Jessica Pablik}

Department of Pathology, Medical Faculty Carl Gustav Carus at the Technical University of Dresden

\section{Katja Evert}

Institute of Pathology, University of Regensburg

\section{Roman Rodionov}


Department of Internal Medicine III, Medical Faculty Carl Gustav Carus at the Technical University of Dresden

\section{Natalia Semenova}

S. P. Botkin Clinical Infectious Disease Hospital, St. Petersburg, Russia

\section{Vsevolod Zinslering}

S. P. Botkin Clinical Infectious Disease Hospital, St. Petersburg, Russia

\section{Raul Gainetdinov}

Institute of Translational Biomedicine, St. Petersburg State University, St. Petersburg

\section{Gustavo Baretton}

Department of Pathology, Medical Faculty Carl Gustav Carus at the Technical University of Dresden

\section{Dirk Lindemann}

Institute of Virology, Medical Faculty Carl Gustav Carus at the Technical University of Dresden

\section{Michaele Solimena}

Paul Langerhans Institute Dresden (PLID)

\section{Barbara Ludwig}

Department of Medicine III, Medical Faculty Carl Gustav Carus at the Technical University of Dresden

\section{Stefan Bornstein ( $\nabla$ stefan.bornstein@uniklinikum-dresden.de )}

Medical Faculty Carl Gustav Carus at the Technical University of Dresden

\section{Letter}

Keywords: COVID-19, SARS-CoV-2, pancreas, metabolic disorders, diabetes, necroptosis

Posted Date: October 12th, 2020

DOI: https://doi.org/10.21203/rs.3.rs-88524/v1

License: (c) (i) This work is licensed under a Creative Commons Attribution 4.0 International License. Read Full License

Version of Record: A version of this preprint was published at Nature Communications on June 10th, 2021. See the published version at https://doi.org/10.1038/s41467-021-23886-3. 


\section{Beta-cells from patients with COVID-19 and from isolated human islets exhibit ACE2, DPP4, and TMPRSS2 expression, viral infiltration and necroptotic cell death}

Charlotte Steenblock ${ }^{1}$, Stefanie Richter ${ }^{2,3}$, Ilona Berger ${ }^{1}$, Marko Barovic ${ }^{4,5}$, Janine Schmid ${ }^{1}$, Undine Schubert ${ }^{1}$, Natalia Jarzebska ${ }^{1,6,7}$, Anne von Mässenhausen ${ }^{1,8}$, Andreas Linkermann ${ }^{1,8}$, Annette Schürmann ${ }^{4,9,10}$, Jessica Pablik ${ }^{11}$, Katja Evert ${ }^{12}$, Roman N. Rodionov ${ }^{1,5}$, Natalia Semenova ${ }^{13,14}$, Vsevolod A. Zinserling ${ }^{13,14}$, Raul R. Gainetdinov ${ }^{15,16}$, Gustavo Baretton ${ }^{11}$, Dirk Lindemann $^{2,3}$, Michele Solimena ${ }^{4,5}$, Barbara Ludwig ${ }^{1,3,4,17}$, Stefan R. Bornstein ${ }^{1,18, *}$

${ }^{1}$ Department of Internal Medicine III, University Hospital Carl Gustav Carus, Technische Universität Dresden, Dresden, Germany.

${ }^{2}$ Institute of Virology, Medical Faculty Carl Gustav Carus, Technische Universität Dresden, Dresden, Germany.

${ }^{3}$ CRTD/DFG-Center for Regenerative Therapies, Technische Universität Dresden, Dresden, Germany.

${ }^{4}$ Paul Langerhans Institute Dresden (PLID) of the Helmholtz Center Munich at the University Hospital

Carl Gustav Carus, Technische Universität Dresden, Dresden, Germany.

${ }^{5}$ German Center for Diabetes Research (DZD e. V.), Neuherberg, Germany

${ }^{6}$ University Centre for Vascular Medicine, University Hospital Carl Gustav Carus, Technische Universität Dresden, Dresden, Germany.

${ }^{7}$ Department of Anesthesiology and Intensive Care Medicine, University Hospital Carl Gustav Carus, Technische Universität Dresden

${ }^{8}$ Biotechnology Center, Technische Universität Dresden, Dresden, Germany.

${ }^{9}$ Department of Experimental Diabetology, German Institute of Human Nutrition Potsdam-

Rehbruecke (DIfE), Potsdam, Germany.

${ }^{10}$ Institute of Nutritional Science, University of Potsdam, Potsdam, Germany.

${ }^{11}$ Department of Pathology, University Hospital Carl Gustav Carus, Technische Universität Dresden, Germany

${ }^{12}$ Institute of Pathology, University of Regensburg, Regensburg, Germany.

${ }^{13}$ S. P. Botkin Clinical Infectious Diseases Hospital, St. Petersburg, Russia.

${ }^{14}$ V. A. Almasov Scientific Research Center, St. Petersburg, Russia.

${ }^{15}$ Institute of Translational Biomedicine, St. Petersburg State University, St. Petersburg, Russia.

${ }^{16}$ St. Petersburg State University Hospital, St. Petersburg State University, St. Petersburg, Russia.

${ }^{17}$ Department of Endocrinology and Diabetology, University Hospital Zurich, Zurich, Switzerland

${ }^{18}$ Diabetes and Nutritional Sciences Division, King's College London, London, UK.

${ }^{*}$ Correspondence: Stefan R. Bornstein

Department of Internal Medicine III

Technische Universität Dresden

Fetscherstrasse 74

01307 Dresden

Germany

Tel.: +493514585955

E-mail: stefan.bornstein@uniklinikum-dresden.de

Keywords: COVID-19, SARS-CoV-2, pancreas, metabolic disorders, diabetes, necroptosis 
Here we report a possible mechanistic link between coronavirus disease 2019 (COVID-19) and diabetes. In addition to its known role on the respiratory system, the human coronavirus SARSCoV-2 has been shown to affect the endocrine system including the pancreas ${ }^{1-4}$. It has been suggested that the virus can induce type 1 diabetes ${ }^{5-8}$. Therefore, we isolated human pancreatic islets and examined the expression of angiotensin-converting enzyme 2 (ACE2) and the protease TMPRSS2, known to be important for SARS-CoV-2 entry ${ }^{9}$. Furthermore, we investigated the expression of an alternative entry receptor, dipeptidyl peptidase-4 (DPP4 also known as CD26) ${ }^{10}$. We found all three proteins expressed in pancreatic beta-cells and confirmed that beta-cells are permissive to infection with SARS-CoV-2 pseudoviruses. Additionally, we performed a comprehensive analysis of ACE2, TMPRSS2 and DPP4 expression in pancreata of 10 patients who died of COVID-19. We report significant variation between the samples and detected the highest levels of ACE2 and DPP4 expression in patients exhibiting SARS-CoV-2 infiltration shown by confocal microscopy, RNAscope and electron microscopy. Furthermore, necroptotic cell death was observed in beta-cells of the COVID-19 patients. Taken together, these data suggest that SARS-CoV-2 viral infection of pancreatic beta-cells may trigger necroptosis and islet impairment. 
Diabetes is associated with an increased risk of severe COVID-19. Furthermore, obesity, hypertension and cardiovascular disorders as common comorbidities of diabetes are all linked with adverse outcomes of COVID-19 ${ }^{3}$. Conversely, new-onset diabetes and severe metabolic complications of preexisting diabetes have been observed in patients suffering from COVID$19^{5-8}$. It has been shown that human pancreatic alpha and beta-cells are permissive to SARSCoV-2 infection ${ }^{11}$. Furthermore, coronavirus infiltration in the pancreas leading to islet damage and acute diabetes was observed after the SARS outbreak in 2002-2003 ${ }^{12}$. For COVID19 patients, a better outcome is observed when a good glycemic control is maintained ${ }^{13}$. Therefore, it has been suggested that ACE2 imbalance in the pancreas causes acute beta-cell dysfunction and a resultant hyperglycemic state ${ }^{14}$. Furthermore, the expression of ACE2 has been shown to be increased upon inflammatory stress suggesting an enhancement of the beta-cell sensitivity to SARS-CoV-2 during inflammatory conditions ${ }^{15}$. Acute pancreatitis following COVID-19 has also been reported ${ }^{16}$.

Here we aimed to examine whether islet injury and acute metabolic complications in the context of an infection with SARS-CoV-2 might be due to direct viral infection of insulinproducing beta-cells. First, we tested different antibodies against the potential receptors and proteases involved in virus entry. We selected three commercially available ACE2 antibodies, two TMPRSS2 antibodies and one DPP4 antibody and tested them on paraffin and cryosections from human pancreas or adrenal tissue (Supplementary Table 1 and Supplementary Fig. 1). After validation of the antibodies, we stained cryosections from isolated primary human islets kept in culture for 1 and 10 days and determined the expression of ACE2, TMPRSS2 and DPP4 (Fig. 1A). All three proteins were detected in the islets, and no difference was observed between day 1 and 10 . 
To examine if human beta-cells are susceptible to infection with SARS-CoV-2, we established a protocol for transduction of isolated human islets with lentiviral vector pseudotypes expressing GFP and containing the SARS-CoV-2 spike (S) protein on their surface (SARS-CoV-2 pseudovirus). Three days after infection, we fixed the intact islets and stained for insulin (Fig. 1B). We observed that after transduction with lentiviral VSV-G pseudotypes (VSV-G pseudovirus), as control for the methodology, nearly all cells in the islets got infected, whereas in islets transduced with SARS-CoV-2 pseudoviruses mostly insulin-producing beta-cells were infected indicating that especially beta-cells are susceptible to infection with SARS-CoV-2 even though both ACE2 and DPP4 are expressed in all islet cells. Only few insulin-producing cells were detected in the center of the islets which is probably due to problems with the ability of the antibody to penetrate the three-dimensional structure of the islets. The same phenomenon could explain why we primarily detected virus-infected cells at the islet surface.

A
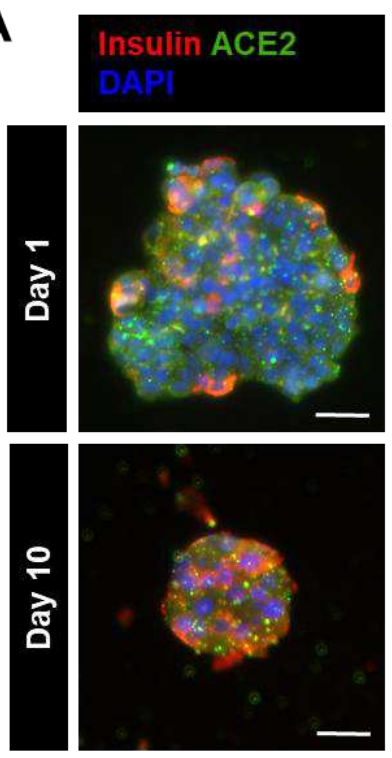
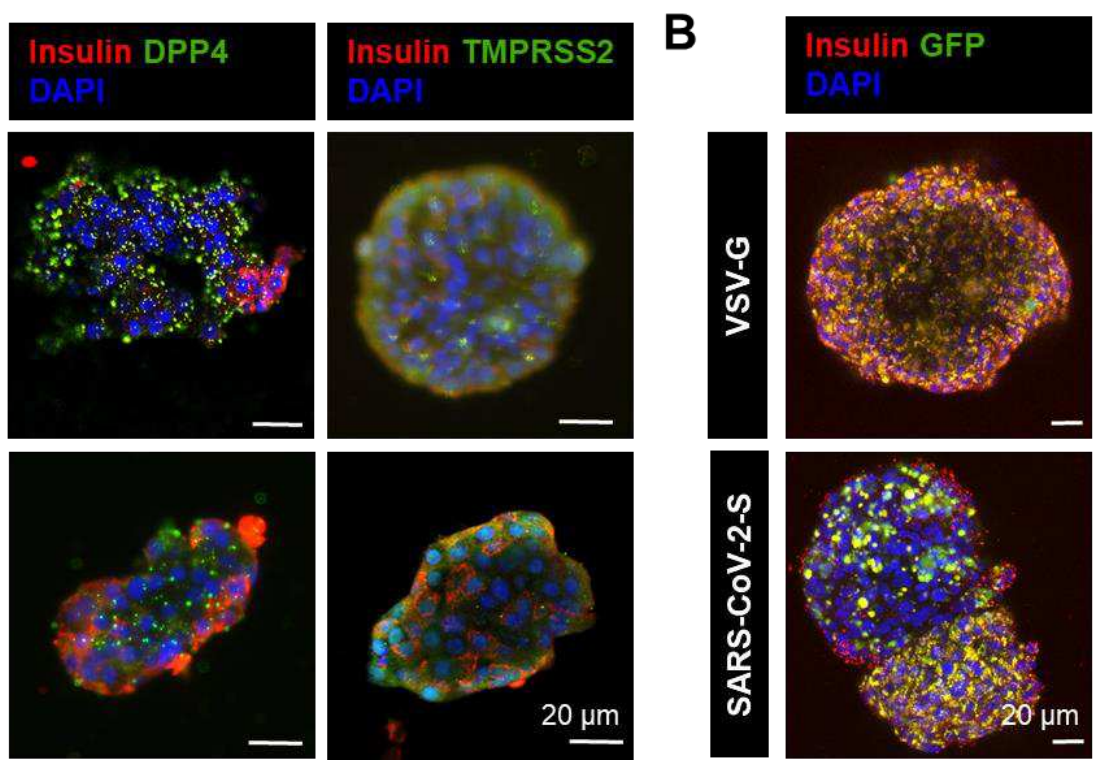

Fig. 1. Human beta-cells are susceptible to infection with SARS-CoV-2. A. Cryosections of isolated human islets cultured for 1 or 10 days were stained for insulin, ACE2, DPP4 and TMPRSS2. Scale bars $=20 \mu \mathrm{m}$. B. Isolated human islets were infected with VSV-G or SARSCoV-2 pseudoviruses expressing GFP and stained for insulin. Z-stacks were acquired and $z$ projection with "Max intensity" was performed using ImageJ software. Scale bars $=20 \mu \mathrm{m}$. 
The expression of ACE2 in the pancreas is a matter of debate and contradictory results have been reported. For example, three different studies showed a higher expression of ACE2 in the exocrine duct cells than in the islets ${ }^{17-19}$, whereas another study showed that ACE2 is preferentially expressed by beta-cells ${ }^{15}$. By single cell sequencing, we have shown that in pancreata from mice, both DPP4 and ACE2 are highly expressed in delta-cells followed by betaand alpha-cells (unpublished data, NATMETAB-A20093633). To clear these contradictory results, we have examined the expression of ACE2, TMPRSS2 and DPP4 in pancreatic tissue from ten patients who died of COVID-19 (Supplementary Table 2). Five (50\%) patients were male, and the patients aged from 44 to 73 years. Two patients exhibited normal weight (BMI $18.5-25 \mathrm{~kg} / \mathrm{m}^{2}$ ), four patients were overweight (BMI $25-30 \mathrm{~kg} / \mathrm{m}^{2}$ ), and four patients were obese $\left(\mathrm{BMI}>30 \mathrm{~kg} / \mathrm{m}^{2}\right)$, two of which were extremely obese $\left(\mathrm{BMI}>40 \mathrm{~kg} / \mathrm{m}^{2}\right)$. One of ten patients (patient \#8) was previously diagnosed with type 2 diabetes. As the tissues are from autopsies, they show varying degrees of autolysis due to prolonged time before autopsy.

In some patients an extensive damage of the islets and especially the beta-cells was observed (Fig. 2-4 and Supplementary Fig. 2 and 3). This damage was seen at varying degrees, and also in patients without previously diagnosed diabetes. In patient \#1 this was validated by the fact that morning blood glucose level increased from $7.3 \mathrm{mmol} / \mathrm{l}$ on the day after admission to 9.0 $\mathrm{mmol} / \mathrm{l} 13$ days later.

In control pancreatic tissue, ACE2 was weakly expressed in pancreatic islets and in fibroblasts (Fig. 2). In the COVID-19 autopsy material, the expression greatly varied between the patients also explaining why previous studies have shown very different results in relation to expression of ACE2 in the pancreas. In some patients, ACE2 was mainly observed in beta-cells (patients \#1 and \#2), whereas in other patients, there was no expression in the islets but in fibroblasts (patients \#4 and \#8). In none of the patients, ACE2 was expressed in the acinar cells 
in the exocrine pancreas (Fig. 2 and Supplementary Fig. 2). DPP4 has previously been shown to be expressed by cells of the immune system as well as on epithelia and endothelia cells in pancreas, lungs, and kidney ${ }^{20}$. In the COVID-19 patients in our study, DPP4 was expressed in both the endocrine and exocrine pancreas (Fig. 2 and Supplementary Fig. 2). In our control tissue, TMPRSS2 was highly expressed in the islets, whereas no expression was observed in the exocrine pancreas. Interestingly, COVID-19 patients showed TMPRSS2 expression in endocrine and exocrine tissue (Fig. 2 and Supplementary Fig. 2).

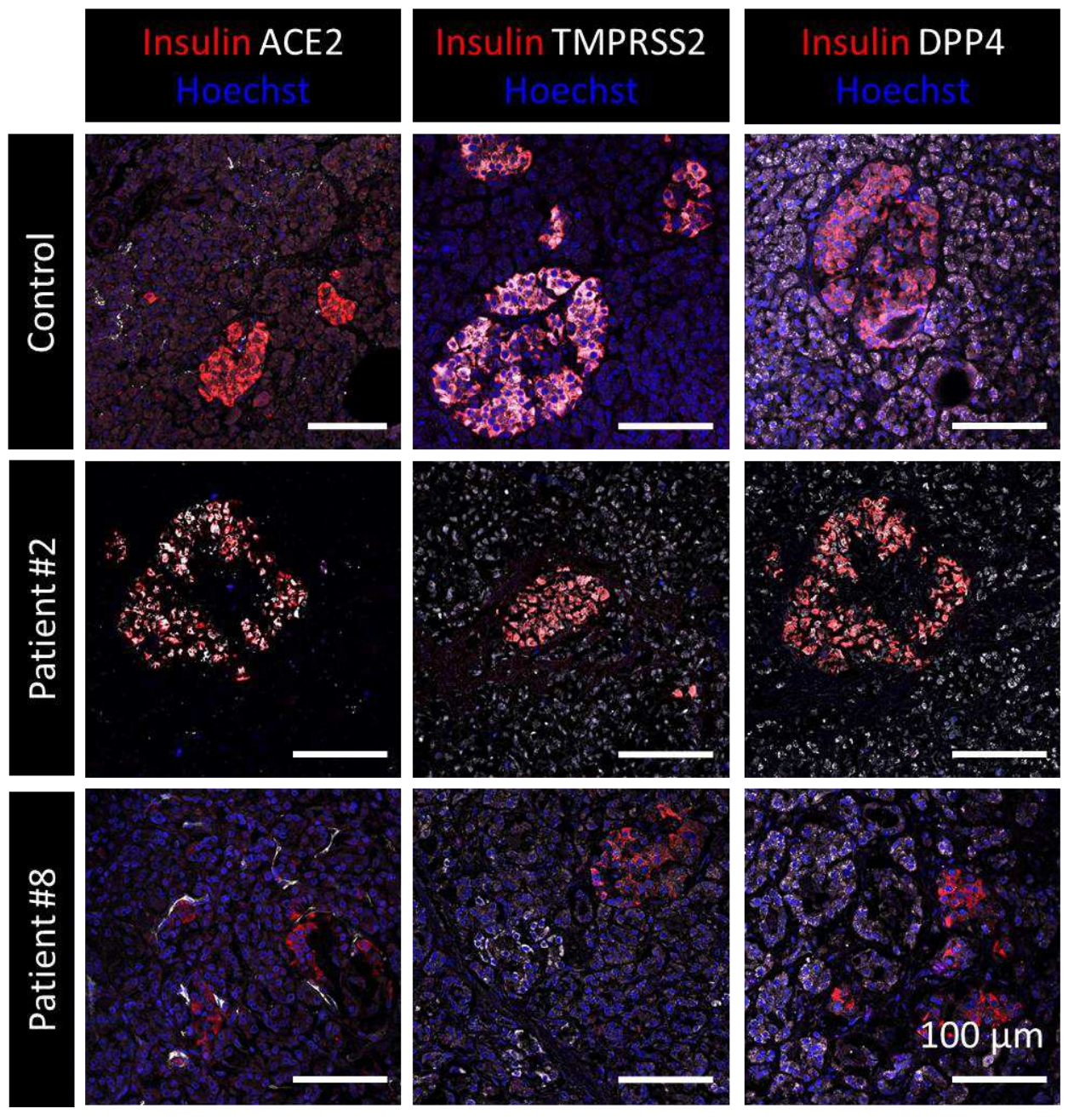

Figure 2. SARS-CoV-2 receptors are expressed in the human pancreas. Pancreas sections from control patients and deceased COVID-19 patients were stained for insulin to mark beta-cells. Additionally, double stainings for ACE2, TMPRSS2 and DPP4 were performed. Representative images are shown. Scale bars $=100 \mu \mathrm{m}$. 
To investigate whether SARS-CoV-2 infect pancreatic cells, we examined if virus particles were present in the pancreas autopsies from the deceased COVID-19 patients. Before performing immunohistochemistry and immunofluorescent stainings, we tested and validated different antibodies recognizing either the SARS-CoV-2 spike (SARS-CoV-2-S) or nucleocapsid (SARSCoV-2-N) protein (Supplementary Table 1 and Supplementary Fig. 1). By staining of SARS-CoV$2-\mathrm{N}$, viral antigens were detected in the endocrine and exocrine pancreata of all the deceased patients but at variable levels (Fig. 3A and Supplementary Fig. 3). Within the islets, the cells positive for viral antigens were found to be insulin-producing beta-cells. The diabetic patient \#8 revealed damaged islets but almost no viral antigens. Those patients showing the highest levels of ACE2 and DPP4 also showed the highest number of cells positive for viral antigens (patients \#1 and \#2). In patient \#2, who showed no ACE2 expression in the exocrine pancreas viral antigens were anyway detectable suggesting that here DPP4 could at least partly be responsible for virus entry. To confirm the immunofluorescent stainings of viral antigens, we used another antibody against SARS-CoV-2-N for immunohistochemistry of tissue from patient \#2. Similar to the immunofluorescent stainings, we observed a high number of cells positive for viral antigens in both the islets and in the exocrine tissue (Fig. 3B). For patient \#1, the paraffin-embedded tissue was re-embedded to perform electron microscopy. After reembedding, the tissue was partly destroyed. Nevertheless, we observed virus-like particles in cells containing insulin secretory granules (Fig. 3C). Additionally, by using RNA in-situ hybridization we detected viral RNA in islets in at least three of the ten patients (\#3, \#6 and \#7) (Fig. 3D + supplementary Fig. 4). In one additional patient (\#8), there was an ambiguous signal, potentially attributable to islet autofluorescence. Archival control (pancreatic tissue collected in 2011) was used to ensure specificity of SARS-CoV-2 probes. In the exocrine tissue 
no viral RNA was detected. In other four of the ten patient tissues (\#1-2, \#4 and \#10), RNA

quality was low because of tissue autolysis and neither INS nor SARS-CoV-2-S was detectable.

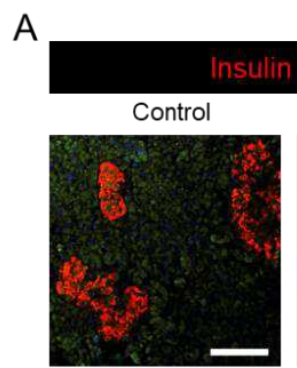

Patient \#3

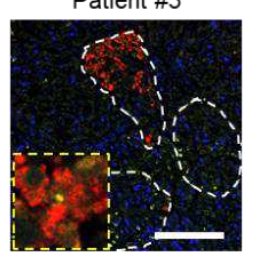

C

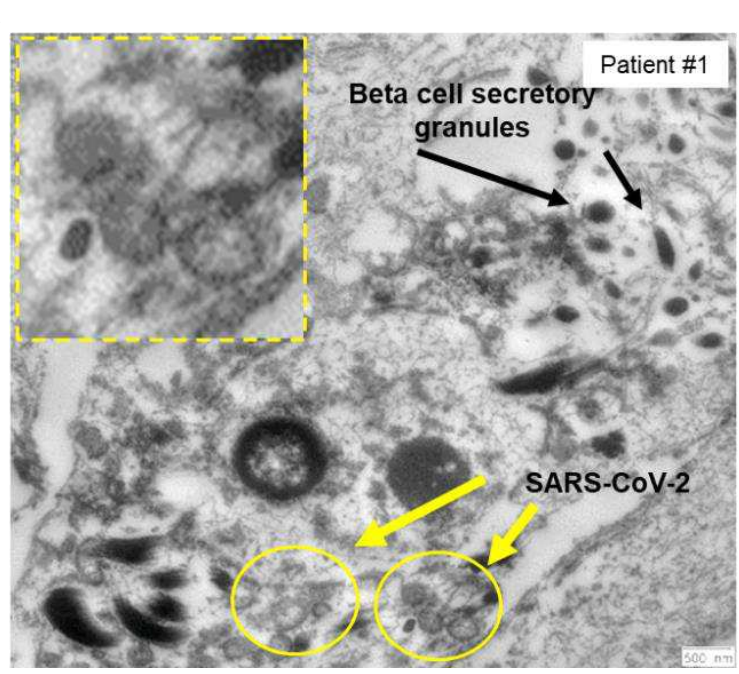

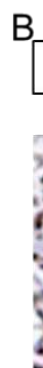

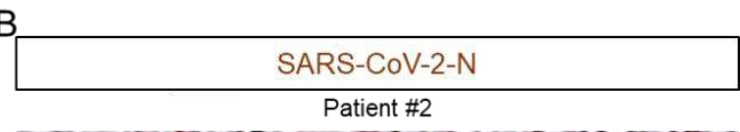

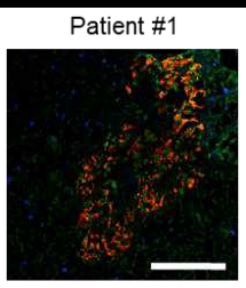

Patient \#7

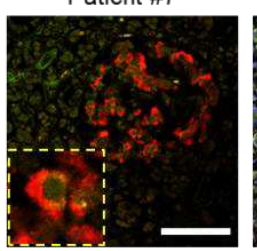

Patient \#8

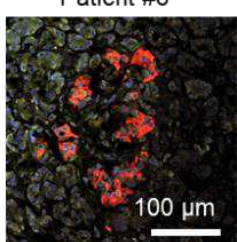

$\mathrm{D}$
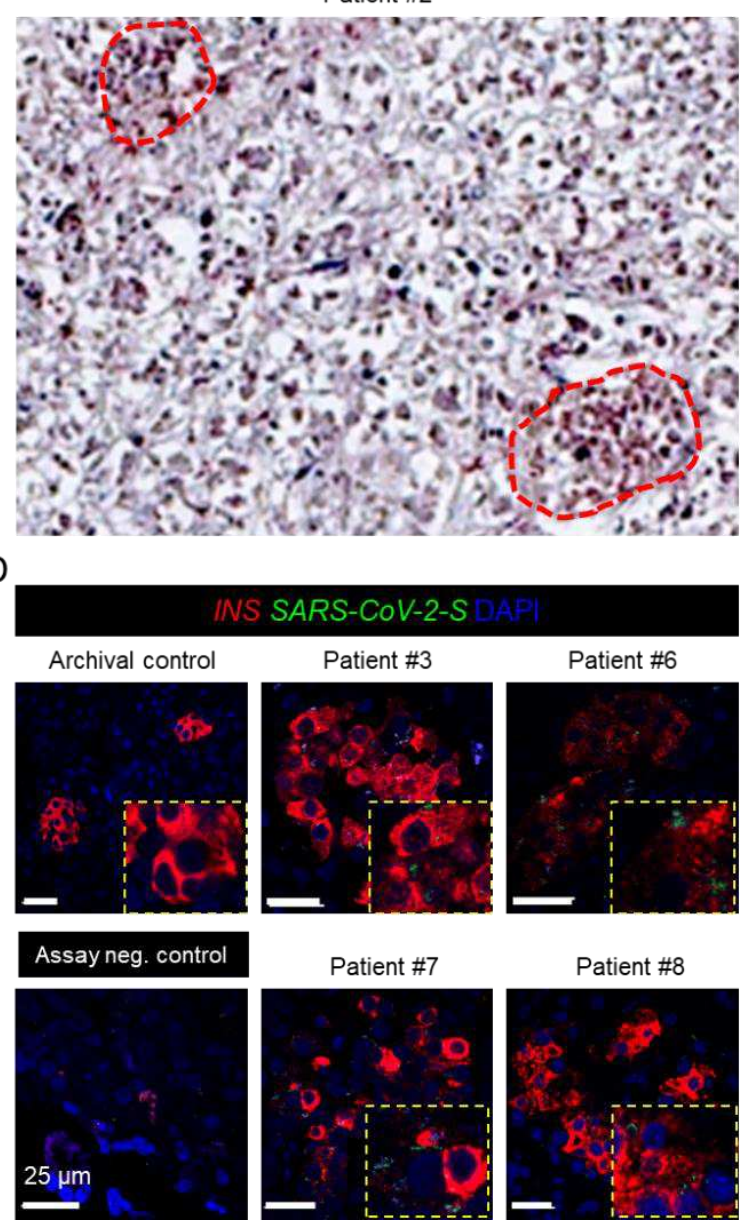

Patient \#8

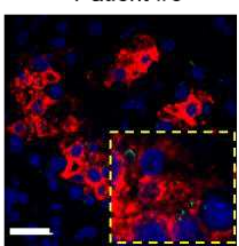

Fig. 3. SARS-CoV-2 infection leads to viral infiltration in the pancreas. A. Immunofluorescent stainings of pancreas sections from COVID-19 patients using antibodies against insulin and SARS-CoV-2-N (sc65653). Islets are indicated in white. Scale bars $=100$ $\mu \mathrm{m}$. B. Immunohistochemistry of pancreas tissue from patient \#2 using a different SARSCoV-2-N antibody (GTX135361). Islets are indicated with red circles. C. Electron microscopy image of pancreas tissue from patient \#1 showing virus-like particles. D. RNA fluorescence in-situ hybridization performed using the RNAscope platform with probes targeting INS and $S A R S-C o V-2-S$. Probes against the bacterial $d a p B$ gene were used as negative control. Scale bars $=25 \mu \mathrm{m}$.

The reason why only small amounts of viral antigens and RNA were detected (Fig. 3A and D) might be due to the fact that all patients, except for \#2, died more than 3 weeks after the initial infection with SARS-CoV-2. This could mean that no or just few active virus particles 
were still present. This is confirmed by the fact that in patient \#2 who died a few days after she got infected, the amount of viral antigens was much higher.

The innate and the adaptive immune systems control surveillance of virally infected cells and remove these by means of apoptosis or necroptosis. Necroptosis is defined as the loss of plasma membrane integrity following receptor interacting kinase 3-mediated phosphorylation of the pseudokinase mixed lineage kinase domain like (MLKL) protein ${ }^{21}$. pMLKL may oligomerize and cause the loss of plasma membrane integrity ${ }^{22}$. This process is opposed by the ESCRT-III membrane repair complex which may be hijacked by viruses ${ }^{23}$. Given the necrotic morphology of the islets of some COVID-19 patients, we hypothesized that SARS-CoV2-triggered necroptosis might be the cause.

To investigate the role of necroptosis in the pancreata, we performed immunofluorescent staining for pMLKL. Remarkably, most COVID-19 patients did not exhibit pMLKL positivity in the exocrine pancreas. However, a clear pMLKL-positivity was detected in beta-cells of COVID19 patient samples while control tissue remained pMLKL-negative (Fig. 4A and Supplementary Fig. 3). We confirmed this finding by immunohistochemistry (Fig. 4B). This suggests that SARSCoV-2 viral infiltration leads to pMLKL positivity, most likely associated with the necroptosis signaling pathway ${ }^{24}$, and might explain why type 1 diabetes has been reported after infection with SARS-CoV-2 ${ }^{5,6}$.

Human corona-virus ( $\mathrm{HCoV}$ ) infection was suggested to trigger necroptosis ${ }^{25}$ even before the COVID-19 crisis. Our detection of pMLKL positivity is in line with this report. Importantly, it is possible to prevent necroptosis by application of receptor-interacting protein kinase $1 / 3$ inhibitors or by necrosulfonamide ${ }^{26}$. Given the massive pro-inflammatory nature of necroptosis ${ }^{27}$, and the positive effects of necroptotic cells on dendritic cell cross-priming ${ }^{28}$, 
a therapeutic inhibition might offer a novel therapeutic approach. However, it remains unclear in which particular patient population inhibition of necroptosis might be clinically helpful.

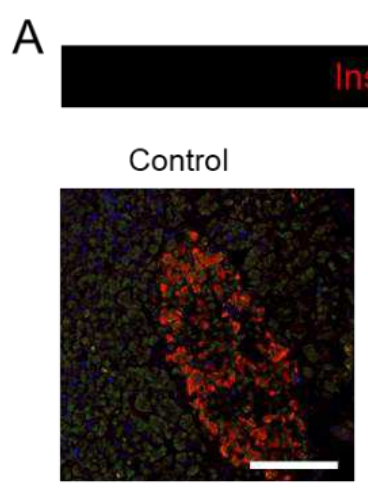

Insulin pMLKL

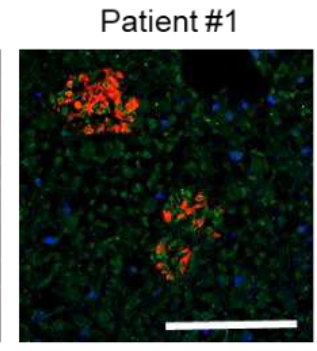

Patient \#5

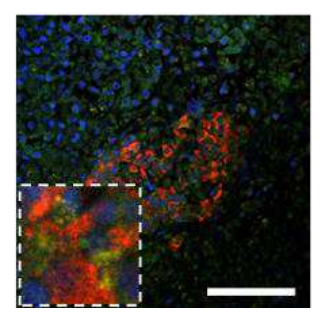

Patient \#7

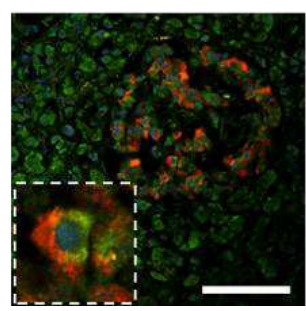

Patient \#2

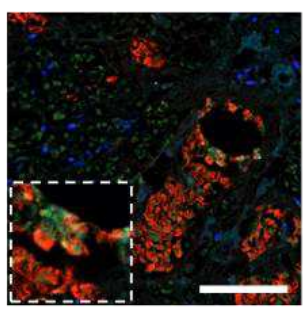

Patient \#8

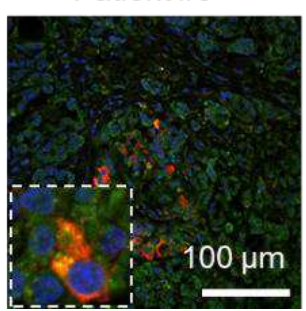

B

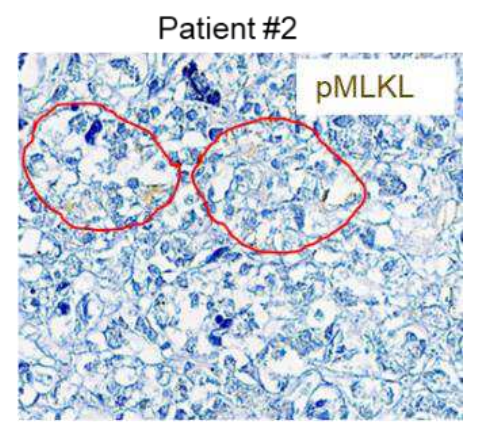

Patient \#7

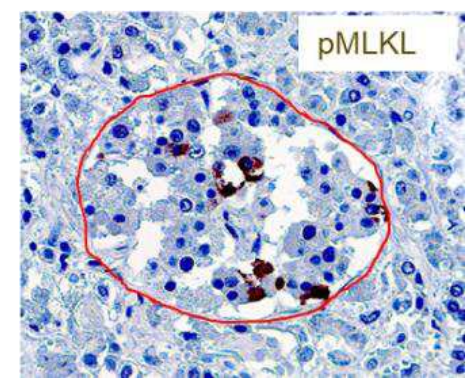

Fig. 4. SARS-CoV-2 infection leads to necroptosis in the pancreas. A. Immunofluorescent stainings of pancreas sections from COVID-19 patients using antibodies against insulin and pMLKL marking necroptotic cells. Scale bars $=100 \mu \mathrm{m}$. B. Immunohistochemistry of pancreas tissue from patient \#2 and \#7 marking pMLKL-positive cells. Islets are indicated in red.

Within the exocrine pancreas, the expression of ACE 2 was very low indicating that virus entry in acinar ductal cells could be mediated via DPP4. In the islets, on the other hand, both DPP4 and ACE2 could be responsible for virus entry. Both potential receptors are established transducers of metabolic signals and pathways regulating inflammation, renal and cardiovascular physiology, and glucose homeostasis ${ }^{29}$. DPP4 inhibitors are widely used for the treatment of type 2 diabetes ${ }^{30}$, but until now there is no clinical evidence that drugs targeting ACE2- or DPP4-related pathways show any benefits or harm in relation to human coronavirus infections ${ }^{29}$. 
Recently, it was shown that age alone does not account for an increased risk of a severe outcome due to COVID-19 infection ${ }^{31}$. This fits with our study, where only four of the ten patients were older than 65 years of age. On the other hand, only two patients (\#1 and \#6) were within the normal weight range. However, in addition to his infection with SARS-CoV-2, patient \#1 was infected with influenza virus. Two female patients died with 44 and 45 years of age, respectively (patients \#2 and \#5), and both were extremely obese. Seven patients were overweight or obese with BMI values between 25 and $35 \mathrm{~kg} / \mathrm{m}^{2}$ (patients \#3, \#4 and \#7-10)) and for patient \#8 it was known that he had type 2 diabetes. These data support the fact that other comorbidities increase the risk of severe outcomes due to COVID-19. Therefore, in addition to the risk of developing type 1 diabetes after infection with SARS-CoV-2, treatment of COVID-19 might have therapeutic implications in people with metabolic disorders and numerous considerations have to be anticipated ${ }^{32-34}$. 


\section{Methods}

\section{Autopsies}

Autopsies were conducted on 10 patients who died of COVID-19 and pancreatic tissue was fixed in formalin and embedded in paraffin. The autopsies were performed at Institute of Pathology at Universitätsklinikum Carl Gustav Carus in Dresden or at Institute of Pathology at Universität Regensburg. The Ethics Committees were informed about the study. Clinical information is provided in Supplementary Table 1. Normal pancreatic tissue was obtained from Zyagen.

\section{Immunohistochemistry/Immunofluorescence}

Paraffin slides were deparaffinized in Neo-Clear (Merck) and rehydrated through a descending graded ethanol series. Antigen retrieval was performed in citrate retrieval buffer $\mathrm{pH} 6.0$, using a Decloaking Chamber NXGEN (Menarini Diagnostics) at $110^{\circ} \mathrm{C}$ for 3 mins.

For immunofluorescence, sections or infected islets fixated in 4\% PFA were blocked in blocking buffer (PBS containing 1\% BSA, 0.1\% Triton X-100, 5\% goat serum for 1 hour at room temperature, followed by incubation with primary antibody diluted in PBS containing $1 \%$ BSA, $5 \%$ goat serum at $4^{\circ} \mathrm{C}$ overnight. Slides were washed in PBS and incubated with appropriate fluorophore-conjugated secondary antibodies in PBS for 2 hours at room temperature. Slides were washed in PBS. Nuclei were stained with 4'-6-diamidino-2-phenylindole (DAPI; Thermo Fisher Scientific) and slides were mounted with fluorescent mounting medium (AquaPoly/Mount; Polysciences).

For immunohistochemistry, deparaffinized sections were blocked and stained using appropriate antibodies and Vectastain $A B C$ Kit Peroxidase and AEC Substrate Kit for 
Peroxidase following the instructions of the manufacturer (Vector Laboratories). Counterstaining with hematoxylin was performed.

\section{Confocal laser scanning microscopy and fluorescence microscopy}

Confocal imaging was performed with a Zeiss LSM 700 inverted confocal laser scanning microscope and ZEN 2010 software (Zeiss). Fluorescence microscopy was done with a Zeiss Axiovert 200M fluorescence microscope and AxioVision software (Zeiss). Image processing and analysis were carried out using ImageJ software.

\section{RNA in-situ hybridization}

RNAscope was performed using the RNAscope ${ }^{\circledR}$ Multiplex Fluorescent Reagent Kit v2 on formalin fixed paraffin embedded tissue using a probe against SARS-CoV-2-S (V-nCoV2019-SC3, cat. No. 848561-C3), and a probe against insulin (Hs-INS, cat. No. 313571) following the instructions of the manufacturer (ACDBio). Internal assay positive control (against POLR2A and $U B C$ ) and negative control (bacterial gene $d a p B$ ) were used in addition to the staining of archival pancreatic tissue collected 9 years ago to ensure specificity of the SARS-CoV-2 probe.

\section{Electron microscopy}

Formalin-fixed and paraffin-embedded pancreas tissue from patient \#1 was reembedded for electron microscopy. Briefly, Toluol (Carl Roth) was added to small pieces of tissue embedded in paraffin and incubated at $40^{\circ} \mathrm{C}$ while shaking. This step was repeated twice followed by rehydration through a descending graded ethanol series. Afterwards, the samples were incubated in $1 \%$ osmium tetroxide $\left(\mathrm{OsO}_{4}\right)$ in pure water for 3 hours followed by 3 times 
washing in pure water. After dehydration through an ascending graded ethanol series the tissue was infiltrated with resin (EtOH/Epon mixture) mixed 3:1 for 3.5 hours. EtOH/Epon mixed 1:1 was then added $\mathrm{ON}$ and next day EtOH/Epon mixed 1:3 was added for 3.5 hours. Pure Epon was added $\mathrm{ON}$ followed by polymerization for 48 hours at $60^{\circ} \mathrm{C}$. Ultrathin sections $(80 \mathrm{~nm})$ were poststained by incubation in $2 \%$ uranyl acetate in pure water for 5 min followed by 3 times washing in pure water and incubation in $0.4 \%$ lead citrate for $2 \mathrm{~min}$. After washing $3 \times 3 \mathrm{~min}$ in pure water samples were analyzed in a CM 10 electron microscope (Philips).

\section{Human islet isolation}

Human islets of Langerhans were isolated from resected pancreas tissue with appropriate consent and ethical approval at the University Hospital Carl Gustav Carus Dresden according to a modified Ricordi method ${ }^{35,36}$. Briefly, Collagenase, neutral protease (Nordmark), and Pulmozyme (Roche) were infused into the main pancreatic duct. Islets were separated from exocrine tissue by centrifugation on a continuous Biocoll gradient (Biochrom AG) in a COBE 2991 cell processor (Lakewood). Following isolation, islets were cultured in RPMI 1640 supplemented with $5.5 \mathrm{mM}$ glucose, $20 \mathrm{mM}$ Hepes, 10\% FBS, 0.1\% penicillin/streptomycin.

\section{Pseudovirus Production}

Lentiviral VSV-G or SARS-CoV-2 S pseudotypes (pseudovirus) were generated by polyethylenimine-mediated transient transfection of 293T packaging cells essentially as described previously ${ }^{37,38}$. Briefly, packaging cells in $10 \mathrm{~cm}$ dishes were co transfected with a lentiviral transfer vector containing a spleen focus forming U3 promoter driven firefly luciferase - EGFP fusion protein reporter cassette (pCL6 Luci-EG wo) and HIV-1 Gag/Pol packaging vector $(\mathrm{pCD} / \mathrm{NL}-\mathrm{BH})$ and the respective glycoprotein packaging vector encoding 
VSV-G (pcziVSV-G) or containing an expression-optimized, C-terminally truncated SARS-CoV-2 spike protein ORF (pCG1 hSARS-CoV-2 S $\triangle \mathrm{c} 18$ ) at a 2:2:1 ratio and $16 \mu \mathrm{g}$ total DNA. Cell-free virus supernatants were harvested $48 \mathrm{~h}$ post transfection and stored in aliquots at $-80^{\circ} \mathrm{C}$ until further use.

\section{Transduction of human islets}

Islets were transferred to low attachment 96 well plates (Corning) and 3 days after isolation they were transduced with cell-free lentiviral pseudotype vector supernatant diluted 1:2 in RPMI 1640 supplemented with $5.5 \mathrm{mM}$ glucose, $20 \mathrm{mM}$ hepes, $10 \%$ FBS, $0.1 \%$ penicillin/streptomycin by spinoculation at $270 \times \mathrm{g}, 30^{\circ} \mathrm{C}$ for $2 \mathrm{~h}$, followed by incubation at $37^{\circ} \mathrm{C}, 5 \% \mathrm{CO}_{2}$ in a tissue culture incubator until fixation in $4 \%$ PFA for immunofluorescence analysis at $72 \mathrm{~h}$ post infection.

\section{Data availability}

The authors declare that the data supporting the findings of this study are available within the paper.

\section{References}

1 Bornstein, S. R., Dalan, R., Hopkins, D., Mingrone, G. \& Boehm, B. O. Endocrine and metabolic link to coronavirus infection. Nat Rev Endocrinol 16, 297-298, doi:10.1038/s41574-020-03539 (2020).

2 Pal, R. \& Banerjee, M. COVID-19 and the endocrine system: exploring the unexplored. J Endocrinol Invest 43, 1027-1031, doi:10.1007/s40618-020-01276-8 (2020).

3 Somasundaram, N. P. et al. The Impact of SARS-Cov-2 Virus Infection on the Endocrine System. J Endocr Soc 4, bvaa082, doi:10.1210/jendso/bvaa082 (2020). 

neuroendocrine stress axis. Mol Psychiatry, doi:10.1038/s41380-020-0758-9 (2020).

5 Chee, Y. J., Ng, S. J. H. \& Yeoh, E. Diabetic ketoacidosis precipitated by Covid-19 in a patient with newly diagnosed diabetes mellitus. Diabetes Res Clin Pract 164, 108166, doi:10.1016/j.diabres.2020.108166 (2020).

6 Hollstein, T. et al. Autoantibody-negative insulin-dependent diabetes mellitus after SARSCoV-2 infection: a case report. Nat Metab, doi:10.1038/s42255-020-00281-8 (2020).

$7 \mathrm{Li}$, J. et al. COVID-19 infection may cause ketosis and ketoacidosis. Diabetes Obes Metab, doi:10.1111/dom.14057 (2020).

8 Rubino, F. et al. New-Onset Diabetes in Covid-19. N Engl J Med, doi:10.1056/NEJMc2018688 (2020).

9 Hoffmann, M. et al. SARS-CoV-2 Cell Entry Depends on ACE2 and TMPRSS2 and Is Blocked by a Clinically Proven Protease Inhibitor. Cell, doi:10.1016/j.cell.2020.02.052 (2020).

10 Vankadari, N. \& Wilce, J. A. Emerging WuHan (COVID-19) coronavirus: glycan shield and structure prediction of spike glycoprotein and its interaction with human CD26. Emerg Microbes Infect 9, 601-604, doi:10.1080/22221751.2020.1739565 (2020).

11 Yang, L. et al. A Human Pluripotent Stem Cell-based Platform to Study SARS-CoV-2 Tropism and Model Virus Infection in Human Cells and Organoids. Cell Stem Cell 27, 125-136 e127, doi:10.1016/j.stem.2020.06.015 (2020).

12 Yang, J. K., Lin, S. S., Ji, X. J. \& Guo, L. M. Binding of SARS coronavirus to its receptor damages islets and causes acute diabetes. Acta Diabetol 47, 193-199, doi:10.1007/s00592-009-0109-4 (2010).

13 Zhu, L. et al. Association of Blood Glucose Control and Outcomes in Patients with COVID-19 and Pre-existing Type 2 Diabetes. Cell Metab 31, 1068-1077 e1063, doi:10.1016/j.cmet.2020.04.021 (2020).

14 Cuschieri, S. \& Grech, S. COVID-19 and diabetes: The why, the what and the how. J Diabetes Complications, 107637, doi:10.1016/j.jdiacomp.2020.107637 (2020).

15 Fignani, D. et al. SARS-CoV-2 receptor Angiotensin I-Converting Enzyme type 2 is expressed in human pancreatic islet $\beta$-cells and is upregulated by inflammatory stress. bioRxiv, 2020.2007.2023.208041, doi:10.1101/2020.07.23.208041 (2020).

16 Kumaran, N. K., Karmakar, B. K. \& Taylor, O. M. Coronavirus disease-19 (COVID-19) associated with acute necrotising pancreatitis (ANP). BMJ Case Rep 13, doi:10.1136/bcr2020-237903 (2020).

17 Coate, K. C. et al. SARS-CoV-2 Cell Entry Factors ACE2 and TMPRSS2 are Expressed in the Pancreas but Not in Islet Endocrine Cells. bioRxiv, 2020.2008.2031.275719, doi:10.1101/2020.08.31.275719 (2020).

18 Kusmartseva, I. et al. ACE2 and SARS-CoV-2 Expression in the Normal and COVID-19 Pancreas. bioRxiv, 2020.2008.2031.270736, doi:10.1101/2020.08.31.270736 (2020).

19 Liu, F. et al. ACE2 Expression in Pancreas May Cause Pancreatic Damage After SARS-CoV-2 Infection. Clin Gastroenterol Hepatol 18, 2128-2130 e2122, doi:10.1016/j.cgh.2020.04.040 (2020).

20 Lambeir, A. M., Durinx, C., Scharpe, S. \& De Meester, I. Dipeptidyl-peptidase IV from bench to bedside: an update on structural properties, functions, and clinical aspects of the enzyme DPP IV. Crit Rev Clin Lab Sci 40, 209-294, doi:10.1080/713609354 (2003).

21 Tonnus, W. et al. The pathological features of regulated necrosis. J Pathol 247, 697-707, doi:10.1002/path.5248 (2019).

22 Sun, L. et al. Mixed lineage kinase domain-like protein mediates necrosis signaling downstream of RIP3 kinase. Cell 148, 213-227, doi:10.1016/j.cell.2011.11.031 (2012).

23 Gong, Y. N. et al. ESCRT-III Acts Downstream of MLKL to Regulate Necroptotic Cell Death and Its Consequences. Cell 169, 286-300 e216, doi:10.1016/j.cell.2017.03.020 (2017).

24 Linkermann, A. \& Green, D. R. Necroptosis. N Engl J Med 370, 455-465, doi:10.1056/NEJMra1310050 (2014). 
25 Meessen-Pinard, M., Le Coupanec, A., Desforges, M. \& Talbot, P. J. Pivotal Role of ReceptorInteracting Protein Kinase 1 and Mixed Lineage Kinase Domain-Like in Neuronal Cell Death Induced by the Human Neuroinvasive Coronavirus OC43. J Virol 91, doi:10.1128/JVI.01513-16 (2017).

26 Degterev, A. \& Linkermann, A. Generation of small molecules to interfere with regulated necrosis. Cell Mol Life Sci 73, 2251-2267, doi:10.1007/s00018-016-2198-x (2016).

27 Tonnus, W. et al. The clinical relevance of necroinflammation-highlighting the importance of acute kidney injury and the adrenal glands. Cell Death Differ 26, 68-82, doi:10.1038/s41418018-0193-5 (2019).

28 Yatim, N. et al. RIPK1 and NF-kappaB signaling in dying cells determines cross-priming of CD8(+) T cells. Science 350, 328-334, doi:10.1126/science.aad0395 (2015).

29 Drucker, D. J. Coronavirus Infections and Type 2 Diabetes-Shared Pathways with Therapeutic Implications. Endocr Rev 41, doi:10.1210/endrev/bnaa011 (2020).

30 Mulvihill, E. E. \& Drucker, D. J. Pharmacology, physiology, and mechanisms of action of dipeptidyl peptidase-4 inhibitors. Endocr Rev 35, 992-1019, doi:10.1210/er.2014-1035 (2014).

31 Romero Starke, K. et al. The Age-Related Risk of Severe Outcomes Due to COVID-19 Infection: A Rapid Review, Meta-Analysis, and Meta-Regression. Int J Environ Res Public Health 17, doi:10.3390/ijerph17165974 (2020).

32 Bornstein, S. R. et al. Practical recommendations for the management of diabetes in patients with COVID-19. Lancet Diabetes Endocrinol 8, 546-550, doi:10.1016/S2213-8587(20)30152-2 (2020).

33 Costa, F. F. et al. Metabolic syndrome and COVID-19: An update on the associated comorbidities and proposed therapies. Diabetes Metab Syndr 14, 809-814, doi:10.1016/j.dsx.2020.06.016 (2020).

34 Katulanda, P. et al. Prevention and management of COVID-19 among patients with diabetes: an appraisal of the literature. Diabetologia 63, 1440-1452, doi:10.1007/s00125-020-05164-x (2020).

35 Ludwig, B. et al. Islet transplantation at the Dresden diabetes center: five years' experience. Horm Metab Res 47, 4-8, doi:10.1055/s-0034-1385876 (2015).

36 Ricordi, C., Lacy, P. E., Finke, E. H., Olack, B. J. \& Scharp, D. W. Automated method for isolation of human pancreatic islets. Diabetes 37, 413-420, doi:10.2337/diab.37.4.413 (1988).

37 Hamann, M. V. et al. Efficient transient genetic manipulation in vitro and in vivo by prototype foamy virus-mediated nonviral RNA transfer. Mol Ther 22, 1460-1471, doi:10.1038/mt.2014.82 (2014). controlled system for efficient pseudotyping of prototype foamy virus vectors. Mol Ther $\mathbf{2 0}$, 1167-1176, doi:10.1038/mt.2012.61 (2012).

\section{Acknowledgements}

We thank Uta Lehnert, Linda Friedrich and Maria Schuster for technical assistance. The imaging facility at the CMCB Technology Platform at TU Dresden is thanked for their assistance with electron microscopy experiments and imaging. The German Registry for COVID-19 Autopsies (DeRegCovid) is thanked for giving us access to the tissues from Regensburg. 
This study was supported by the Deutsche Forschungsgemeinschaft (DFG, German Research foundation) project no. 314061271, TRR 205/1: “The Adrenal: Central Relay in Health and Disease" (C.S., B.L. and S.R.B.) and project no. 288034826, IRTG 2251: "Immunological and Cellular Strategies in Metabolic Disease" (C.S., M.S., B.L. and S.R.B.). This work was additionally supported by a DFG Heisenberg-Professorship to A.L. (project no. 324141047). R.R.G was supported by Saint Petersburg State University, Saint Petersburg, Russia (project no. $51143531)$.

\section{Author Contributions}

C.S., A.L., B.L., D.L. and S.R.B. designed research; J.P., G.B. and K.E. performed the autopsies of the COVID-19 patients. J.S., U.S. and B.L. isolated and cultured the primary human islets. S.R. and D.L. performed the transduction with the pseudoviruses. C.S., I.B., N.J., A.v.M, R.N.R., R.R.G., N.S. and V.A.Z. optimized and validated the immunofluorescent stainings. C.S. performed the stainings on the COVID-19 tissues. M.B. and M.S. performed the RNA scope experiments. C.S., A.S., A.L. and S.R.B. analyzed data. C.S. and S.R.B. wrote the paper. All authors read and approved the manuscript. C.S. and S.R.B. supervised the study.

\section{Competing interests}

The authors declare no competing interests. 


\section{Figures}

A
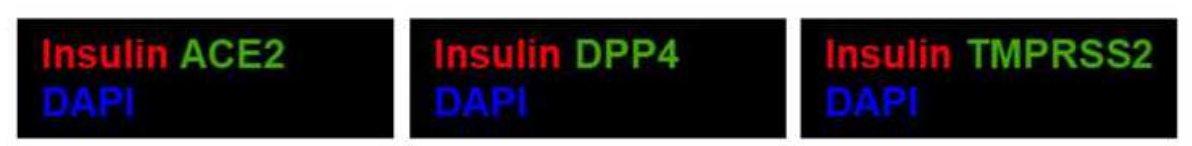

B
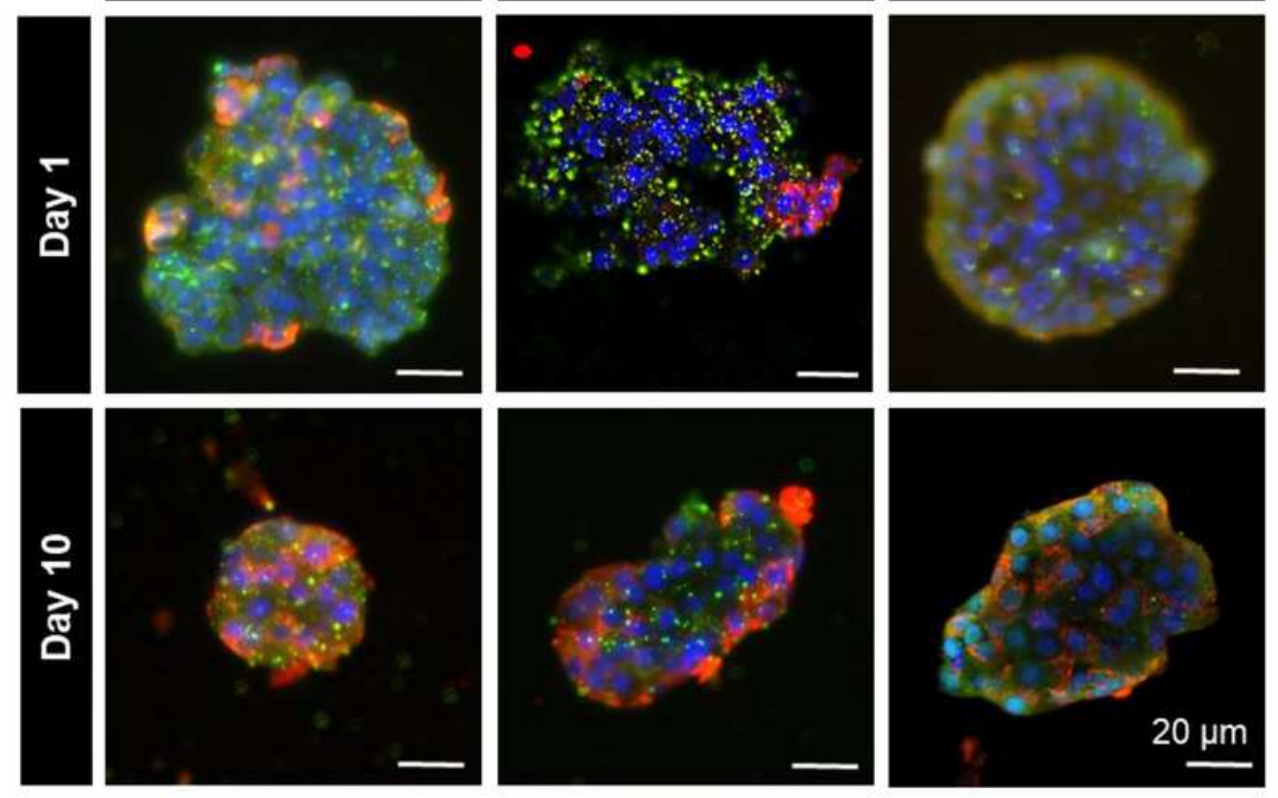
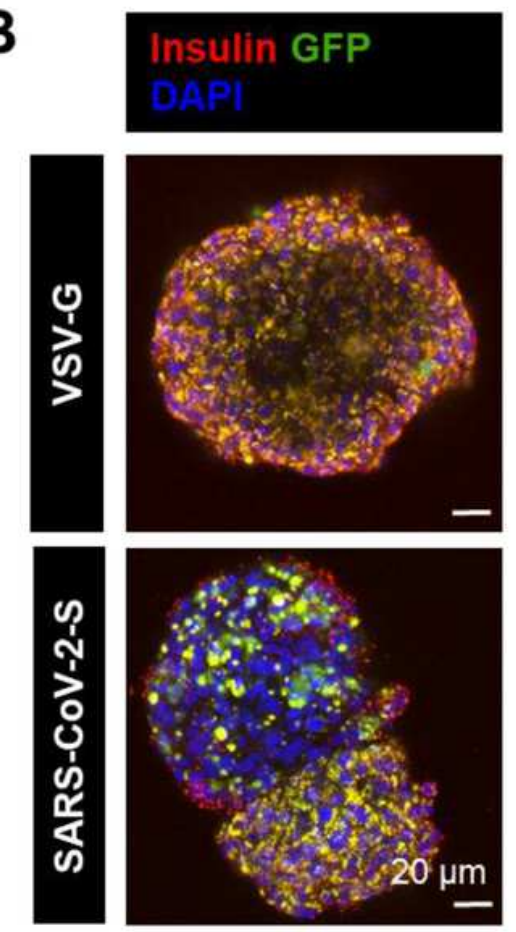

\section{Figure 1}

Human beta-cells are susceptible to infection with SARS-CoV-2. A. Cryosections of isolated human islets cultured for 1 or 10 days were stained for insulin, ACE2, DPP4 and TMPRSS2. Scale bars = $20 \mu \mathrm{m}$. B. Isolated human islets were infected with VSV-G or SARS-CoV-2 pseudoviruses expressing GFP and stained for insulin. Z-stacks were acquired and z projection with "Max intensity" was performed using Image J software. Scale bars $=20 \mu \mathrm{m}$. 


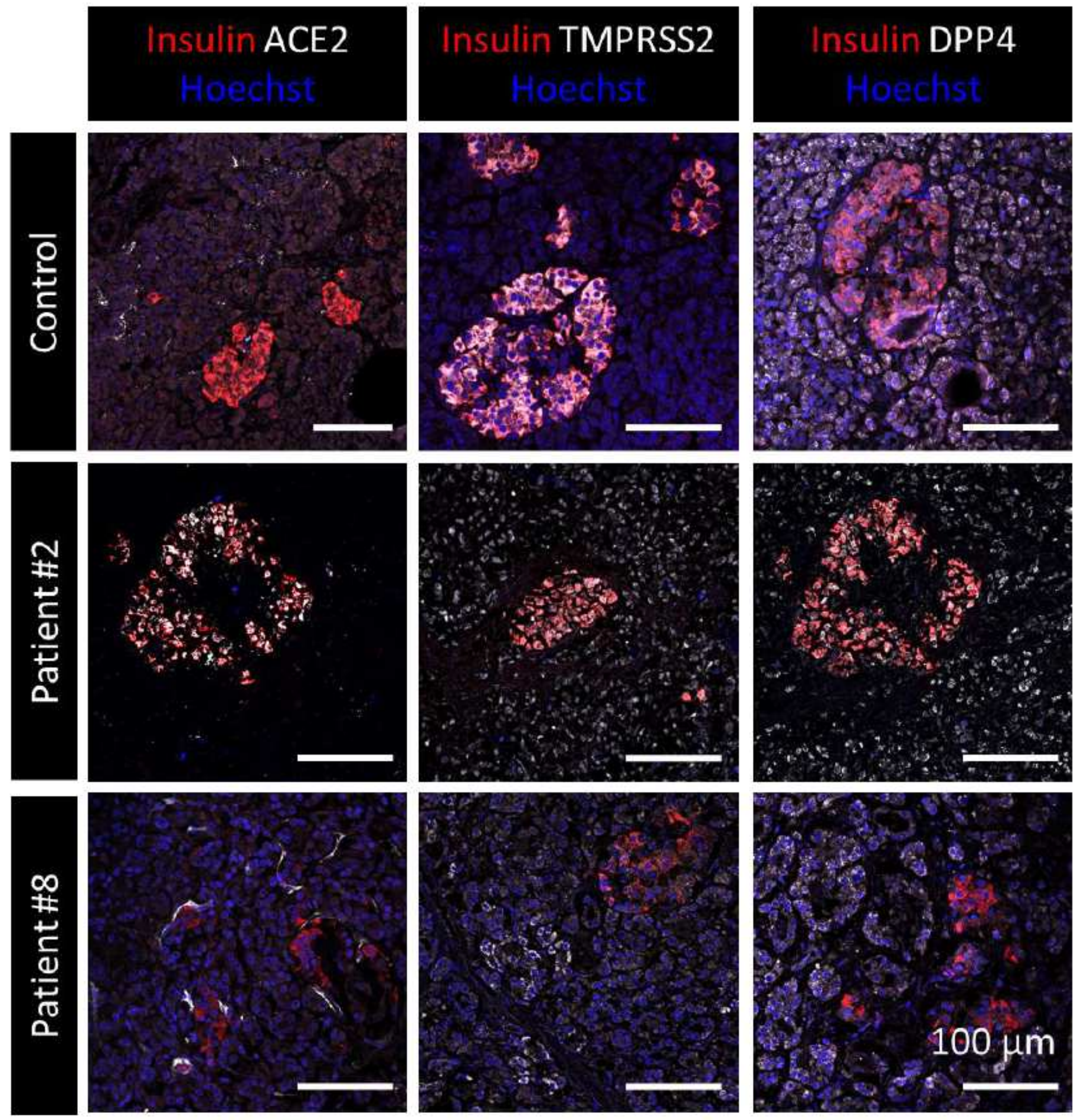

Figure 2

SARS-CoV-2 receptors are expressed in the human pancreas. Pancreas sections from control patients and deceased COVID-19 patients were stained for insulin to mark beta-cells. Additionally, double stainings for ACE2, TMPRSS2 and DPP4 were performed. Representative images are shown. Scale bars = $100 \mu \mathrm{m}$. 


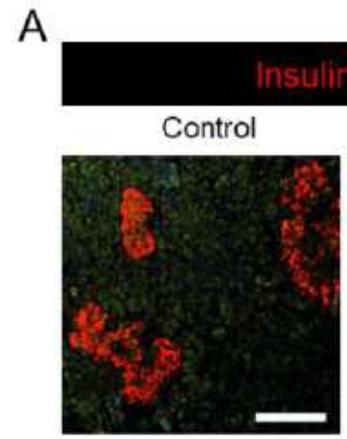

Patient \#3

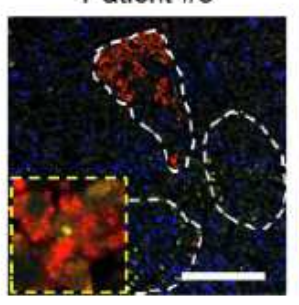

C

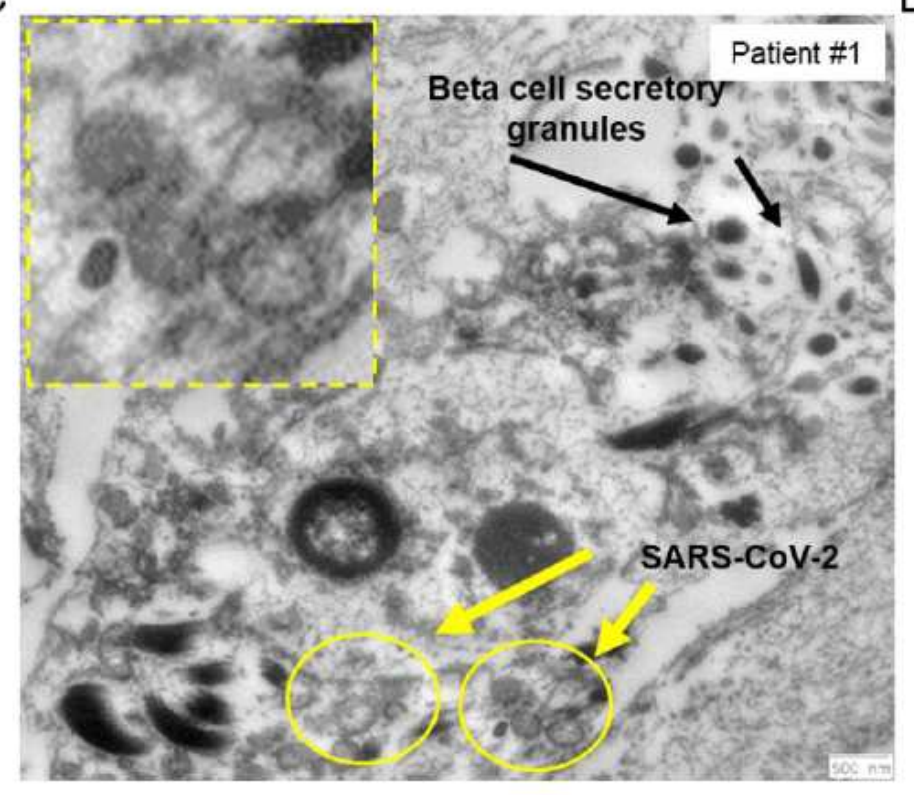

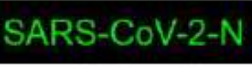

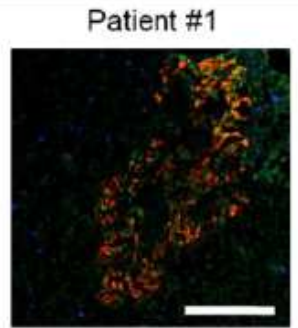

Patient \#7

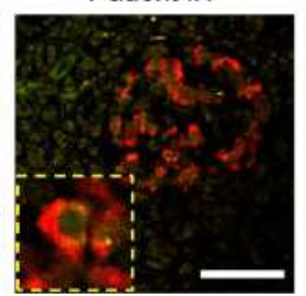

Patient \#2

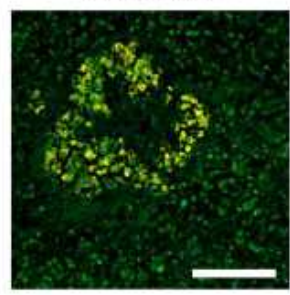

Patient \#8

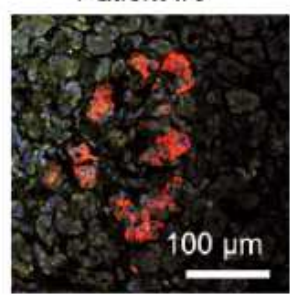

B

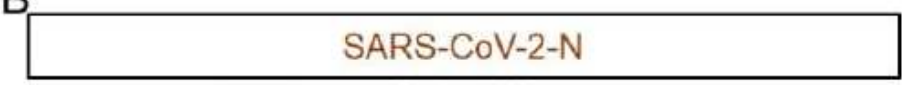

Patient \#2

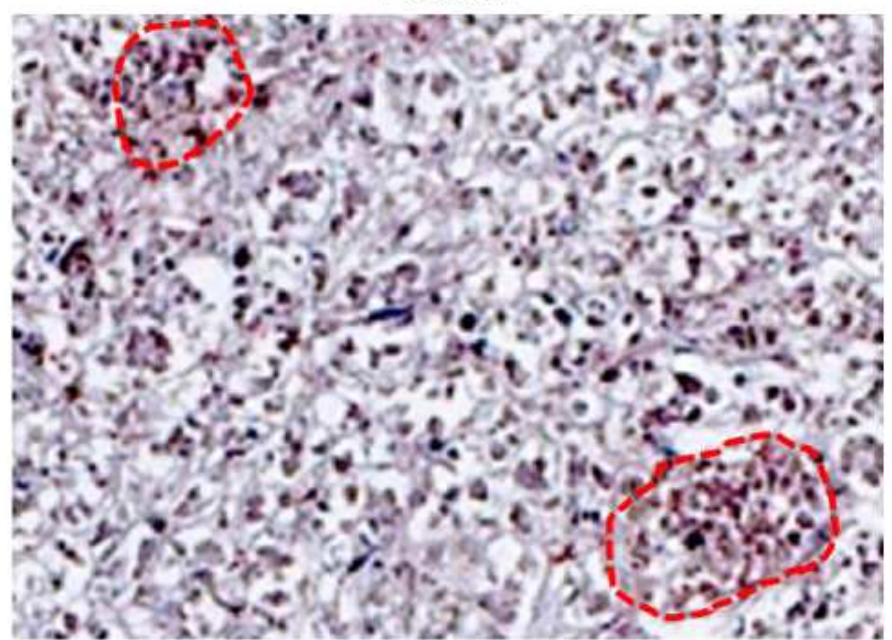

D

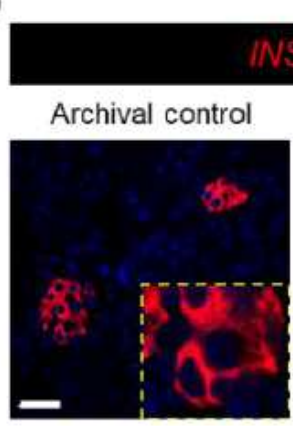

INS SARS-COV-2-S
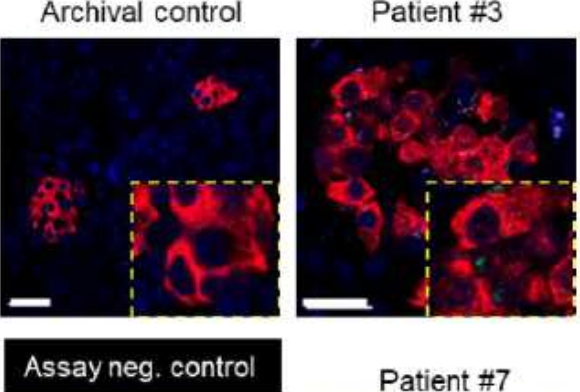

Patient \#7
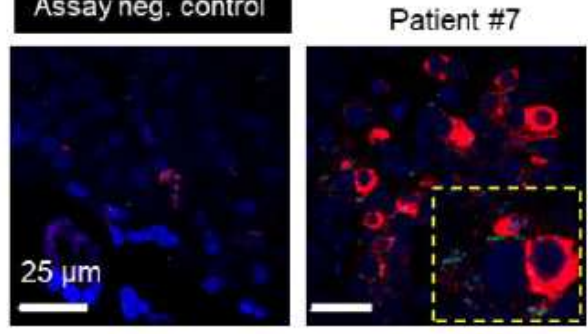

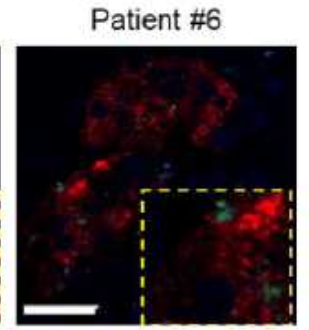

Patient \#8

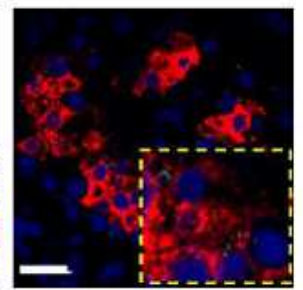

\section{Figure 3}

SARS-CoV-2 infection leads to viral infiltration in the pancreas. A. Immunofluorescent stainings of pancreas sections from COVID-19 patients using antibodies against insulin and SARS-CoV-2-N (sc65653). Islets are indicated in white. Scale bars $=100 \mu \mathrm{m}$. B. Immunohistochemistry of pancreas tissue from patient \#2 using a different SARS-CoV-2-N antibody (GTX135361). Islets are indicated with red circles. C. Electron microscopy image of pancreas tissue from patient \#1 showing virus-like particles. D. RNA fluorescence in-situ hybridization performed using the RNAscope platform with probes targeting INS and SARS-CoV-2-S. Probes against the bacterial dapB gene were used as negative control. Scale bars $=25 \mu \mathrm{m}$. 
A

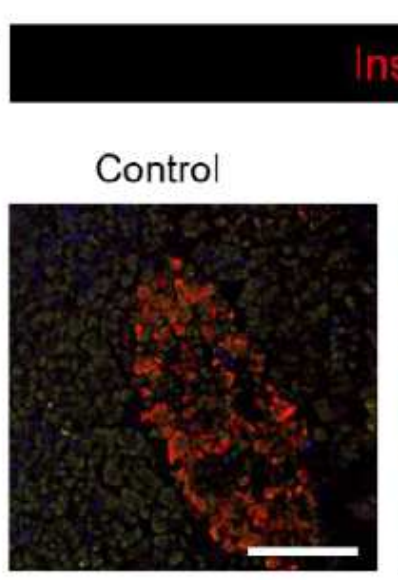

Insulin pMLKL

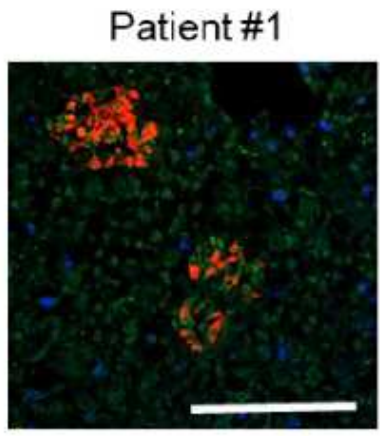

Patient \#5

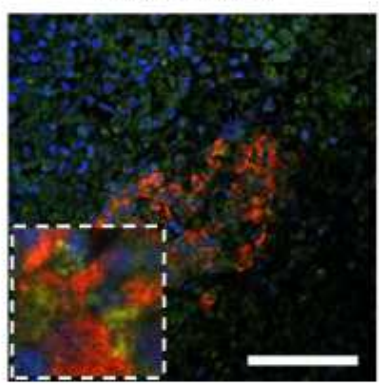

Patient \#7

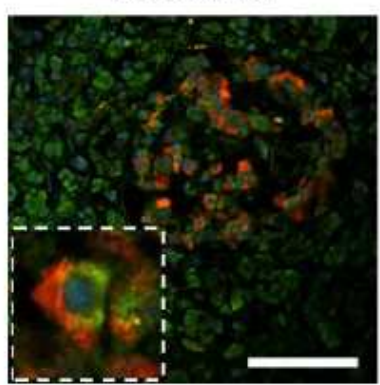

B

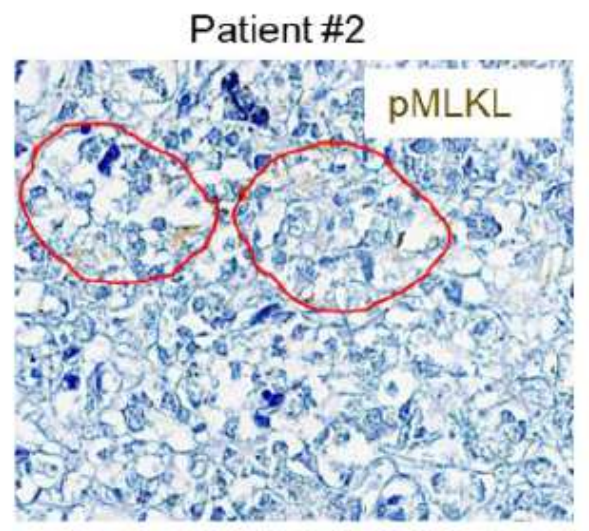

\section{Patient \#7}

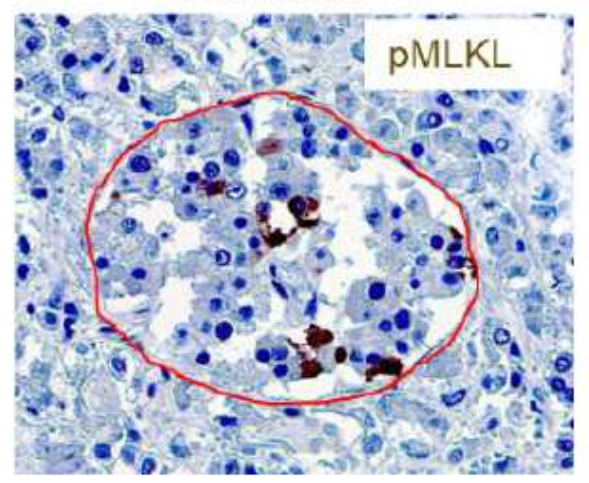

\section{Figure 4}

SARS-CoV-2 infection leads to necroptosis in the pancreas. A. Immunofluorescent stainings of pancreas sections from COVID-19 patients using antibodies against insulin and pMLKL marking necroptotic cells. Scale bars $=100 \mu \mathrm{m}$. B. Immunohistochemistry of pancreas tissue from patient \#2 and \#7 marking pMLKL-positive cells. Islets are indicated in red.

\section{Supplementary Files}

This is a list of supplementary files associated with this preprint. Click to download.

- Supplementaryfiles.pdf 